\title{
O mundo midiático no mundo da beleza: como as esteticistas adquirem os seus produtos cosméticos
}

\author{
Jeanete Moussa Alma ${ }^{1}$ \\ Magda Lucy Ribeiro Botelho da Costa²
}

\begin{abstract}
Resumo: Por meio de pesquisa quantitativa e qualitativa realizada com 250 profissionais da área de estética, durante o $5^{\circ}$ Congresso Científico Latino-Americano de Estética, Saúde e Bem-Estar, de 28 a 31 de agosto de 2010, em São Paulo, observou-se como as esteticistas escolhem os produtos cosméticos necessários para o desempenho de suas atividades, atentando-se para a influência da mídia impressa e da internet nesse processo. Analisou-se, assim, o comportamento da profissional no momento da escolha, diante da diversidade de ativos e de lançamentos que esse mercado oferece.
\end{abstract}

Palavras- chave: estética, mídia, cosméticos, pesquisa, esteticistas.

Abstract: Here is disclosed a quantitative and qualitative survey involving 250 professionals from esthetics area during the 5th Scientific Latin America Conference of Esthetics, Health and Welfare, from August, 28th to 31st, 2010, in São Paulo. The purpose was to verify how cosmetic products are chosen by beauty consultants in order to attend their activities as well as evaluate the press and internet influence on their option. Besides, it was evaluated the professionals' behavior at the choice moment given to the diversity and launches offered by this market.

Keywords: esthetics, media, cosmetics; search, esthetics consultant. 
O dicionário Aurélio define a esteticista como a profissional especialista em assuntos de beleza e saúde. Já a CBO (Classificação Brasileira de Ocupações), publicada em 10 de janeiro de 2011, no site do Ministério do Trabalho e Emprego, identifica a ocupação no mercado de trabalho, para fins classificatórios junto aos registros administrativos e domiciliares, sob a descrição "3221- tecnólogos e técnicos em terapias alternativas e estéticas" (as profissões estão sob o mesmo código e se diferenciam de acordo com suas atribuições) como: esteticista facial, esteticista corporal, tecnólogo em cosmetologia e estética, tecnólogo em cosmetologia facial e corporal, tecnólogo em estética, tecnólogo em estética facial, corporal e capilar, tecnólogo em estética e cosmética e técnico em estética.

Suas atribuições, dentro dessa descrição 3221, que engloba determinadas atividades em terapias alternativas e estética, são:

Aplicar procedimentos estéticos e terapêuticos manipulativos, energéticos e vibracionais. Os procedimentos terapêuticos visam a tratamentos de moléstias psiconeurofuncionais, músculo esquelético e energético; além de patologias e deformidades podais. Para tanto, avaliam as disfunções fisiológicas, sistêmicas, energéticas, vibracionais e inestéticas dos clientes. Recomendam a prática de exercícios, o uso de essências florais e fitoterápicos com objetivo de reconduzir ao equilíbrio energético, fisiológico e psico-orgânico; bem como cosméticos e óleos essenciais, visando sua saúde e bem-estar. Algumas profissionais fazem uso de instrumental perfurocortantes, medicamentos de uso tópico e órteses; outros aplicam métodos das medicinas oriental e convencional (MTE).

O IBGE (Instituto de Geografia e Estatística), consultado em fevereiro de 2011, declara não existir qualquer dado oficial atualizado a respeito do número de integrantes da categoria. Matérias em revistas de grande circulação divulgam que há cerca de 100 mil profissionais no país, sem oferecer a fonte de tal estatística, contrapondo o Ministério do Trabalho e Emprego, que, por meio de sua assessoria de imprensa, em novembro de 2008, constatou a presença de mais de 5 mil profissionais no Brasil (aproximadamente, $70 \%$ deles concentrados na região Sudeste). 
Essa disparidade de informações pode ser explicada pela situação de informalidade a que as profissionais estão sujeitas, pois a regulamentação de sua carreira não foi concedida, embora muito solicitada, pelos órgãos competentes. Outro fator seria a falta de organização da classe trabalhadora. A Febrape (Federação Brasileira dos Profissionais Esteticistas) ainda informa que a área de atividade é ocupada, principalmente, por mulheres (90\%).

Segundo a Abihpec (Associação Brasileira de Produtos de Higiene Pessoal, Perfumaria e Cosmética), a constante evolução da indústria da beleza nos últimos 14 anos alavancou um crescimento médio deflacionado de 10,5\%. A participação da mulher no mercado de trabalho e os lançamentos constantes de produtos, atendendo as diferentes necessidades do mercado e ao aumento da expectativa de vida, com a preocupação de conservar a jovialidade, são alguns dos aspectos que mantêm essa expansão.

Diante dessas informações, para a profissional se manter nesse mercado, é preciso investir em cursos de atualização e se informar a respeito de novas tecnologias usadas no desenvolvimento de produtos cosméticos e de aparelhos que promovam um diferencial em seus serviços.

O primeiro curso superior cadastrado pelo MEC (Ministério da Educação) surgiu em 2001 e foi organizado por uma das autoras deste artigo, professora Jeanete Moussa Alma. O curso de pós-graduação surgiu logo em seguida. Hoje, há 79 cursos na área, espalhados pelo Brasil, segundo o MEC. Em relação ao curso técnico, só o Senac (Serviço Nacional de Aprendizagem Comercial) formou, em 2010, 9.881 alunos, em 14 Estados do país.

Outro dado interessante é o da empresa Nova Imagem Cosméticos ${ }^{3}$, sediada em São Paulo, e que já formou cerca de mil técnicas em estética, desde que obteve autorização no MEC para o curso técnico, em 2000. Além disso, cerca de 1.700 já passaram pelo curso de qualificação profissional em estética facial e 1.800 pelo de estética corporal. 
A gama de ocupações no setor inclui também o trabalho com franquias de empresas, as representações de produtos e aparelhos, os postos em clínicas de cirurgia plástica, hotéis e cruzeiros e o atendimento em pré e pósoperatórios e em spas, entre outras funções.

A estética atrai a atenção de todas as camadas sociais, de pessoas de diferentes níveis culturais e econômicos, e os produtos variam de preço e atendem as mais distintas finalidades. Daí a importância da qualificação profissional. É imprescindível conhecer as técnicas, estar bem informada e estabelecer tratamentos que inspirem segurança e garantam eficácia. As empresas de produtos cosméticos para profissionais e as que atingem diretamente o consumidor final têm desenvolvido estratégias diferentes para chamar a atenção para seus produtos e garantir sua fatia de mercado.

Em 2003, a Avon contava com a colaboração de 800 mil revendedoras no país e hoje tem um milhão. A Natura, na mesma época, contava com 300 mil; hoje, são 1.029 mil. As duas empresas têm um exército de mulheres divulgando as marcas, executando um trabalho direto de divulgação de conceito e de valores por meio dos produtos e, por fim, elas são um "termômetro" da aceitação desses valores por parte das consumidoras.

Já os produtos para profissionais utilizados pelas esteticistas são divulgados por meio de oficinas e workshops. Geralmente, as empresas da área possuem um centro técnico para sanar dúvidas e apresentar lançamentos. Outra característica é o desenvolvimento de ações como incentivo às metas; apoio de marketing, com folhetos, catálogos e banners, sem nenhum ônus para quem trabalha com a marca; e encontros (congressos, feiras e simpósios) para atualização.

Essas profissionais são a ponte entre a empresa e o consumidor final e atuam nas vendas, indicando os cuidados em casa, com a linha de produtos "cliente", uma continuidade do processo executado na cabine de estética, em clinicas, em spas etc. Aqui, quem executa o feedback é a esteticista; ela é o canal para o público final. 
Sobre os resultados das ações nos meios de comunicação, três empresas desse setor, Valmari ${ }^{4}$, Vitaderm ${ }^{5}$ e Buona Vita6, com mais de 20 anos no mercado, não têm como quantificar o número de profissionais que adquirem seus produtos através do retorno das mídias. Segundo elas, não é possível separar os dados estatisticamente. O investimento em mídia é maciço, e a constante preocupação em desenvolver pesquisas para aprimorar os produtos, assim como a sedimentação da marca no mercado de consumo, são fatores que as posicionam favoravelmente nesse âmbito.

Outros mecanismos, como um dos adotados pela empresa Especiarias Cosméticas, que também dá suporte técnico às profissionais, possibilita a quantificação do número de esteticistas que adquirem seus cosméticos. Nenhum produto é vendido sem um treinamento mínimo para a profissional. Além disso, a venda direta ao consumidor não é feita, salvo no caso de clientes que vêm indicadas pelas profissionais que as atendem. Como todas as esteticistas são cadastradas, é fácil analisar a influência dessa divulgação indireta às consumidoras finais.

Diferentes formas de comunicação, para criar empatia e estabelecer relacionamento de confiança e segurança ao adquirir um produto, são fundamentais para criar laços com a marca. Essa afetividade na relação consultora/cliente e profissional/cliente vem por meio de recursos que se aliam ao sustentáculo da propaganda.

Quando a propaganda, por meio de veículos impressos direcionados e internet, atinge primeiro a profissional esteticista para depois chegar ao público final, uma das premissas é que esse produto seja atraente quanto à tecnologia empregada. Consumir com qualidade e consciência são obrigações da esteticista, pois nesse momento ela assume o papel da cuidadora que presta serviços em beleza mas também oferece qualidade de vida e bem-estar. A profissional passa a ser a agente da reestruturação da imagem, da autoestima e da autoconfiança de quem a procura. Esse tripé diz respeito à condição de jovialidade e aos 
cuidados que qualquer pessoa, em qualquer área de atuação, necessita perante um mercado de trabalho tão competitivo.

\section{O belo e a comunicação}

São Paulo, Rio de Janeiro e Minas são os três Estados com maior número de empresas atuantes no mercado de produtos de higiene pessoal, perfumaria e cosméticos, seguidos pelo Paraná. Ao todo, existem no Brasil 1.659 empresas voltadas para o setor e, em 2009, os brasileiros gastaram R $\$ 24,9$ bilhões com esses produtos (Abihpec).

Nesse mercado competitivo, os investimentos em pesquisa e tecnologia de ponta são armas para as empresas de cosméticos manterem-se na vanguarda. Além disso, as estratégias de propaganda e marketing dão visibilidade ao produto e à marca e incentivam o consumo.

A empresa Vitaderm, por exemplo, investe cerca de R\$ 1 milhão anualmente em mídia impressa e eletrônica. Em internet, todos os anúncios ou aparições em reportagens provêm de parcerias, trabalho com assessoria de imprensa e patrocínios com produtos. Um veículo não substitui o outro em termos de divulgação, e os retornos são compensatórios nos dois casos. ${ }^{7}$

No ano passado, a Valmari investiu $R \$ 280$ mil em mídia impressa e internet. As ações da empresa visam, dentre outros objetivos, o aprimoramento do pessoal e o suporte às franquias, que estão em contato permanente com o público-alvo: profissionais e consumidor final.

A Buona Vita não quis citar valores. Mas, no ano passado, a empresa diz que investiu em diversas ações de incentivo e apoio aos revendedores e também no desenvolvimento de um novo site, que terá canais de interatividade e sistema de e-commerce.

A empresa Especiarias Cosméticas investiu, no ano passado, pouco mais de $\mathrm{R} \$ 20$ mil em mídia impressa e internet e R\$50 mil em apostilas, catálogos 
explicativos e internet. Os gastos em mídia impressa superam os feitos com a internet, porque é um trabalho muito próximo ao que se faz em uma sala de aula, como afirma a gerente comercial, Lilia França.

O belo e a propaganda estão intrinsecamente ligados pela busca da satisfação dos desejos de melhor aparência e, consequentemente, de melhores oportunidades. "O Brasil é o país da América Latina que tem o maior gasto anual com cosméticos por habitante, US $\$ 116,20$, seguido do Chile, US\$96,50 e da Argentina, US\$74,90" (Instituto Euromonitor-2009).

A concorrência entre anunciantes e/ou marcas tem colaborado para o surgimento de diversas estratégias ao longo do tempo, como forma inovadora de tornar conhecido o produto, ou serviço ou marca perante o consumidor e ainda, com o advento da internet, facilitar a oferta deles em praças de difícil acesso (SHIMP, 2002).

Sedução e persuasão ganham uma grande dimensão neste contexto, afinal o ato da persuasão passa pelo ritual da sedução e isto significa em primeiro momento que, quanto mais atraente o produto, mais as pessoas desejarão adquiri-lo e menor será o intervalo entre a data que sai da fábrica e aquela em que é vendido. Mas a estética do produto só é percebida através da estética dada a ele através da comunicação, que tem na propaganda esta possibilidade de transformar todo e qualquer produto esteticamente o mais agradável possível, como também o próprio anúncio se converte numa realização estética (GALINDO, 2002, 128).

O belo é trabalhado na estética da construção da propaganda de cosméticos para que atinja, seduza e convença a profissional esteticista que trabalha a beleza em cada cliente - no sentido de lhe construir uma nova imagem, satisfazer os seus anseios e levá-lo a adquirir produtos que facilitarão ainda mais a reconquista da imagem desejada. "Convencer é construir algo no campo das ideias. Quando convencemos alguém, esse alguém passa a pensar como nós. Persuadir é construir no terreno da ação: quando persuadimos alguém, esse alguém realiza algo que desejamos que ele realize" (RIBEIRO, 2005, p. 410). 
Nesse universo que instiga às transformações, ao aperfeiçoamento, ao resgate do "eu", por meio da imagem apurada no espelho, como essa profissional decide o que é melhor, mais adequado, mais eficaz aos seus olhos e posteriormente aos olhos da cliente? Serão a mídia impressa e internet linguagens e imagens poderosas capazes de influenciar suas escolhas?

As novas tecnologias trouxeram mudanças profundas no sistema de comunicação de massas. Até a década de 90, mídia impressa, rádio e TV compunham o cenário da informação. Mas, com o advento da internet, a troca de informações tornou-se mais ágil, e uma nova linguagem, muito mais imediatista, foi instituída - a interatividade em tempo real, gerando um vínculo com os internautas no sentido de descobrir seus desejos e realizá-los em um tempo mais curto.

No primeiro semestre de 2008 , as compras on-line somaram $R \$ 3,8$ bilhões (45\% mais do que igual período de 2007). O ano fechou em $R \$$ 8,2 bilhões (crescimento de $30 \%$ na comparação com 2007). A previsão para o primeiro semestre de 2009 era de $R \$ 4,5$ bilhões, mas, mesmo com crise, o faturamento foi de $R \$ 4,8$ bilhões, $27 \%$ a mais em relação ao mesmo período de 2008. O valor médio das compras é de $R \$ 323$. A previsão é que o ano feche em $R \$ 10,6$ bilhões.

(...) A internet se tornou o terceiro veículo de maior alcance no Brasil, atrás apenas de rádio e TV; $87 \%$ dos internautas utilizam a rede para pesquisar produtos e serviços. Antes de comprar, $90 \%$ dos consumidores ouvem sugestões de pessoas conhecidas, enquanto $70 \%$ confiam em opiniões expressas online (INSTITUTO IBOPE NIELSEN).

Entre os brasileiros com mais de 12 anos, 54\% costumam acessar a internet ( 81,3 milhões de pessoas). O principal local de acesso é a lan house $(31 \%)$, seguido da própria casa $(27 \%)$ e da casa de parentes de amigos, com $25 \%$ (abril/2010). O Brasil é o $5^{\circ}$ país com o maior número de conexões à internet (F/NAZCA).

De outubro de 2009 a outubro de 2010, o número de usuários ativos (que acessam a internet regularmente) cresceu 13,2\%, atingindo 41,7 milhões de pessoas. Somado às pessoas que possuem acesso no trabalho, o número salta para 51,8 milhões. E $38 \%$ das pessoas acessam a web diariamente; $10 \%$, de quatro a seis vezes por semana; $21 \%$, de duas a três vezes por semana; $18 \%$, uma vez por semana. Somando os dados, $87 \%$ dos internautas brasileiros entram na internet semanalmente (INSTITUTO IBOPE NIELSEN). 
Neste artigo, temos a mídia impressa em veículos direcionados à área de estética e a internet como fontes de informação para as profissionais. As linguagens são diferentes; as abordagens, distintas; e a finalidade de captar as clientes assume uma forma especial de captar a atenção e o desejo. O mundo virtual e o papel apresentam o objeto. Mas adquiri-lo é uma questão de usar as ferramentas adequadas para criar o caminho para essa aquisição.

\section{Metodologia}

Durante o $5^{\circ}$ Congresso Científico Latino-Americano de Estética Saúde e Bem-Estar, na Beauty Fair, foram entregues 400 questionários com 15 perguntas referentes ao tema da pesquisa, sobre a influência da mídia impressa e da internet na aquisição de produtos cosméticos profissionais por esteticistas e sobre o desempenho de suas atividades. Foram devolvidos 250 deles.

O questionário foi baseado na pesquisa de campo do trabalho de conclusão do curso de cosmetologia e estética "A influência do belo no consumo de cosméticos", das alunas Graziele Brugnago e Rosa Fidêncio Vieira, na Universidade do Vale do Itajaí, em Balneário Camboriú (SC), no ano de 2007. As informações da pesquisa formaram o suporte deste artigo por falta de bibliografia adequada e dados oficiais.

\section{Discussão}

Entre as 250 entrevistadas, separadas por grupos de idades de dez em dez anos, o maior número de esteticistas localizou-se na faixa de 29 aos 39 anos, com 86 profissionais; de 18 a 28 anos, foram 78; de 40 a 50 anos, 55; de 51 a 61 anos, 26 e, com 62 anos ou mais, cinco profissionais (com $62,63,65,83$ e 87 anos).

Do total das pesquisadas, $57 \%$ frequentou o curso técnico regular e $40 \%$, os cursos livres. Os cursos de graduação refletem $26 \%$ das pesquisadas e os de 
pós-graduação, $11 \%$. As que fazem cursos livres somam 36\%; tecnólogo, 5\%; e as que cursam pós-graduação correspondem a 3\%. O país conta com cursos superiores em quase todos os Estados, oferecendo chances de desenvolvimento na carreira e abrindo o leque de participação no mercado de trabalho.

Partindo-se do princípio de que a categoria ainda não é regulamentada e de que existem informações discrepantes a respeito de suas atividades, esta amostra representa um início para futuros estudos acerca da importância do trabalho realizado por essas profissionais.

A área em que mais atuam, dentro das atribuições que lhe são conferidas, é a facial e corporal (com 70\%); a facial, corporal e capilar representa $12 \%$ das profissionais; na terceira posição, vem a área facial, com 6\% de esteticistas; e a área corporal tem mesmo índice. A média de atuação é de cinco anos; em seguida, vem as profissionais que estão com mais de 10 anos de atividades. Um dado interessante é que em todos os grupos, separados por um intervalo de dez anos, existem estudantes. Esse fato demonstra que há condições de crescimento e aprimoramento profissional, ampliando as possibilidades de participação no campo da beleza. Das entrevistadas, por exemplo, duas esteticistas, com 65 e 83 anos, respectivamente, cursam pós-graduação.

Constatou-se que um número significativo de profissionais, 57\%, escolhem as novidades em produtos para trabalhar em suas cabines de estética, clínicas, spas etc. As novidades em cosméticos são, por exemplo, os lançamentos que apresentam novas tecnologias em ativos para diversas finalidades. Aparecem, em seguida, as compras em oficinas e workshops que as empresas de produtos cosméticos oferecem, e o marketing boca a boca - a velha forma de comunicação que instiga à compra, mas que só funciona se quem realiza a prática sabe mais do que aquele que recebe a informação. Nos Estados Unidos, por exemplo, a tática do boca a boca não é uma atividade voluntária, é paga. 
A rede de televisão norte-americana CBS produziu recentemente um documentário abordando o tema e mostrou os planos de marketing promocional de algumas empresas no país que se utilizaram do "boca a boca contratado" para divulgar seus lançamentos. As vantagens, de acordo com fabricantes e agências organizadoras, são a abordagem informal e o custo, já que o valor do projeto de promoção se mostra bem mais barato do que outros meios de divulgação para lançamentos de novas marcas ou produtos (SEBRAE, 2004).

O boca a boca, que também pode ser chamado de "micromarketing", parte do princípio de que a mensagem de marketing dirigida a cada indivíduo é muito mais poderosa porque é mais pessoal - podendo atingir, a princípio, uma quantidade maior de pessoas do que a mensagem veiculada pelos meios tradicionais, bastando para isso que seja repassada por indivíduos com grande número de contatos e dispostos a promover determinados produtos a quem Ihes der ouvidos (UNIVERSIDADE DE WARTHON, 2005).

O trabalho de divulgação do consultor das empresas foi escolhido, depois do boca a boca, como fator determinante para a aquisição de cosméticos. Por meio dele, a profissional de estética se informa sobre os lançamentos, as promoções, os kits, os ativos etc. Já os itens "propaganda em veículos especializados" e "internet" ficaram com $6 \%$ da preferência, em um primeiro momento.

Quanto ao critério de escolha dos cosméticos, quase todas as profissionais assinalaram os ativos como item determinante desse processo. Verificou-se que existe a preocupação em tomar ciência a respeito dos princípios ativos contidos no produto e da sua utilização. A "confiabilidade da marca" foi a escolha de mais da metade do total das participantes. É sinônimo de um conjunto de ações, projetos, promoções, motivações e investimentos que a empresa constrói ao longo de sua participação no mercado.

Questionadas mais uma vez sobre a importância da mídia impressa para definir a aquisição de um produto, apenas $35 \%$ do total responderam negativamente. 
Tabela 1

\section{Mídia impressa é importante para definir a compra}

\begin{tabular}{lccccc} 
Idades & Sim & $\%$ & Não & $\%$ & Total \\
\hline $18-28$ & 54 & $22 \%$ & 24 & $10 \%$ & 78 \\
\hline $29-39$ & 56 & $22 \%$ & 27 & $11 \%$ & 83 \\
\hline $40-50$ & 34 & $14 \%$ & 21 & $8 \%$ & 55 \\
\hline $51-61$ & 9 & $4 \%$ & 16 & $6 \%$ & 25 \\
\hline $62+$ & 4 & $2 \%$ & & & 4 \\
\hline Total & 157 & $64 \%$ & 88 & $35 \%$ & 245 \\
\hline S/ resposta & & & & & 4
\end{tabular}

\section{Gráfico 1*}

Mídia impressa é importante para definir a compra

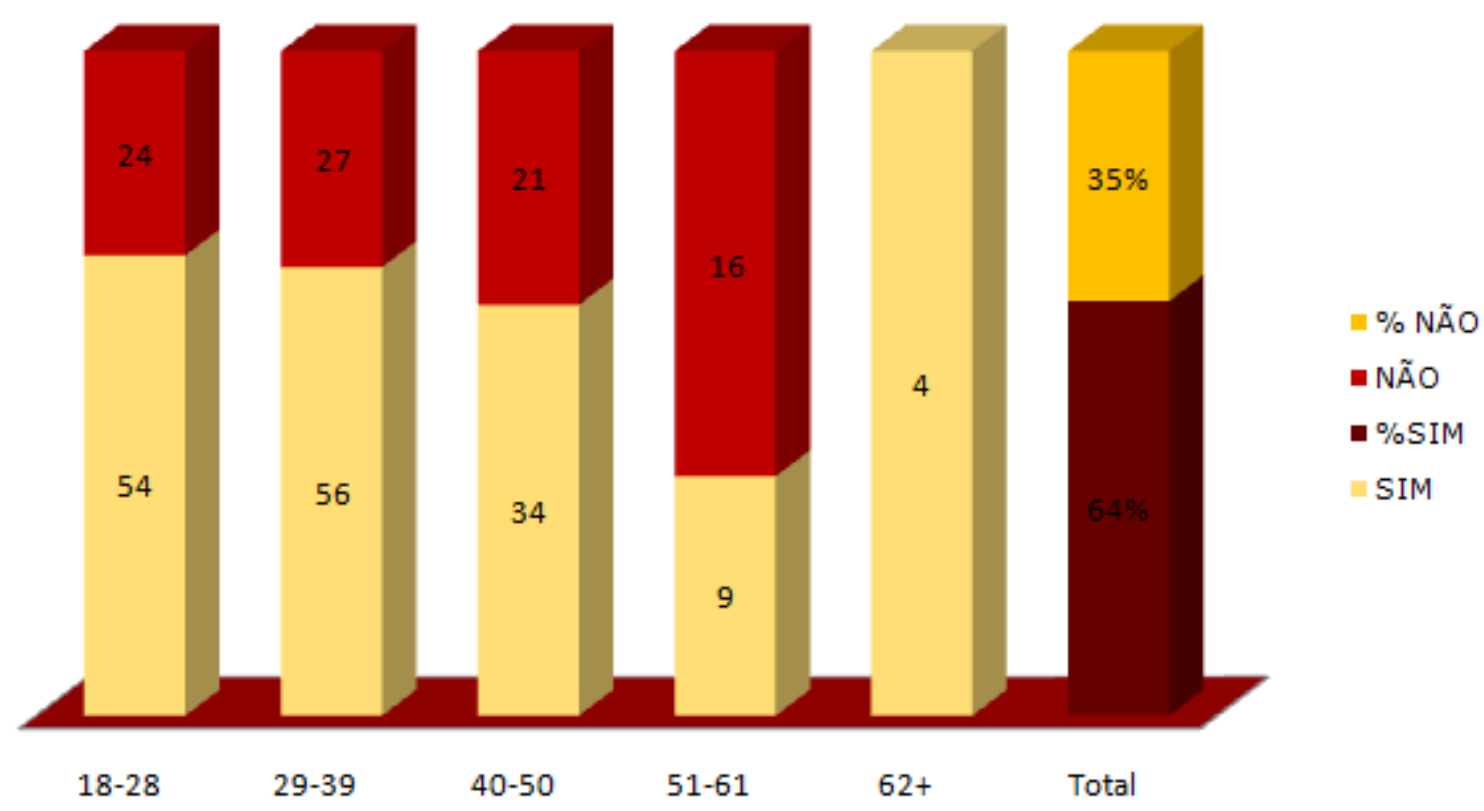

*Das 250 profissionais, 1\% não respondeu; 64\% disseram "sim"; e 35\%, "não" 


\section{Faces da informação}

A rapidez com que uma informação é divulgada pode influenciar na escolha de um cosmético. Cerca de $70 \%$ esteticistas, do total das entrevistadas, asseguraram que a internet comprova a eficácia de um produto por meio de um acesso mais rápido à informação. De todos os grupos, o da faixa de 29 a 39 anos foi o que deu mais respostas afirmativas, seguido do grupo de 18 a 28 anos.

Tabela 2

\begin{tabular}{|c|c|c|c|c|c|c|c|}
\hline Idades & Sim & & Não & & Total & $\%$ & Ausente \\
\hline $18-28$ & 58 & $23 \%$ & 20 & $8 \%$ & & & \\
\hline $29-39$ & 63 & $25 \%$ & 20 & $8 \%$ & & & \\
\hline $40-50$ & 36 & $14 \%$ & 19 & $8 \%$ & & & \\
\hline $51-61$ & 18 & $7 \%$ & 7 & $3 \%$ & & & \\
\hline $62+$ & 3. & $1 \%$ & 1. & $0 \%$ & & & \\
\hline Total & 178 & $70 \%$ & 67 & $27 \%$ & 245 & $97 \%$ & $3 \%$ \\
\hline
\end{tabular}

\section{Gráfico 2*}

Internet comprova eficácia do produto por acesso rápido

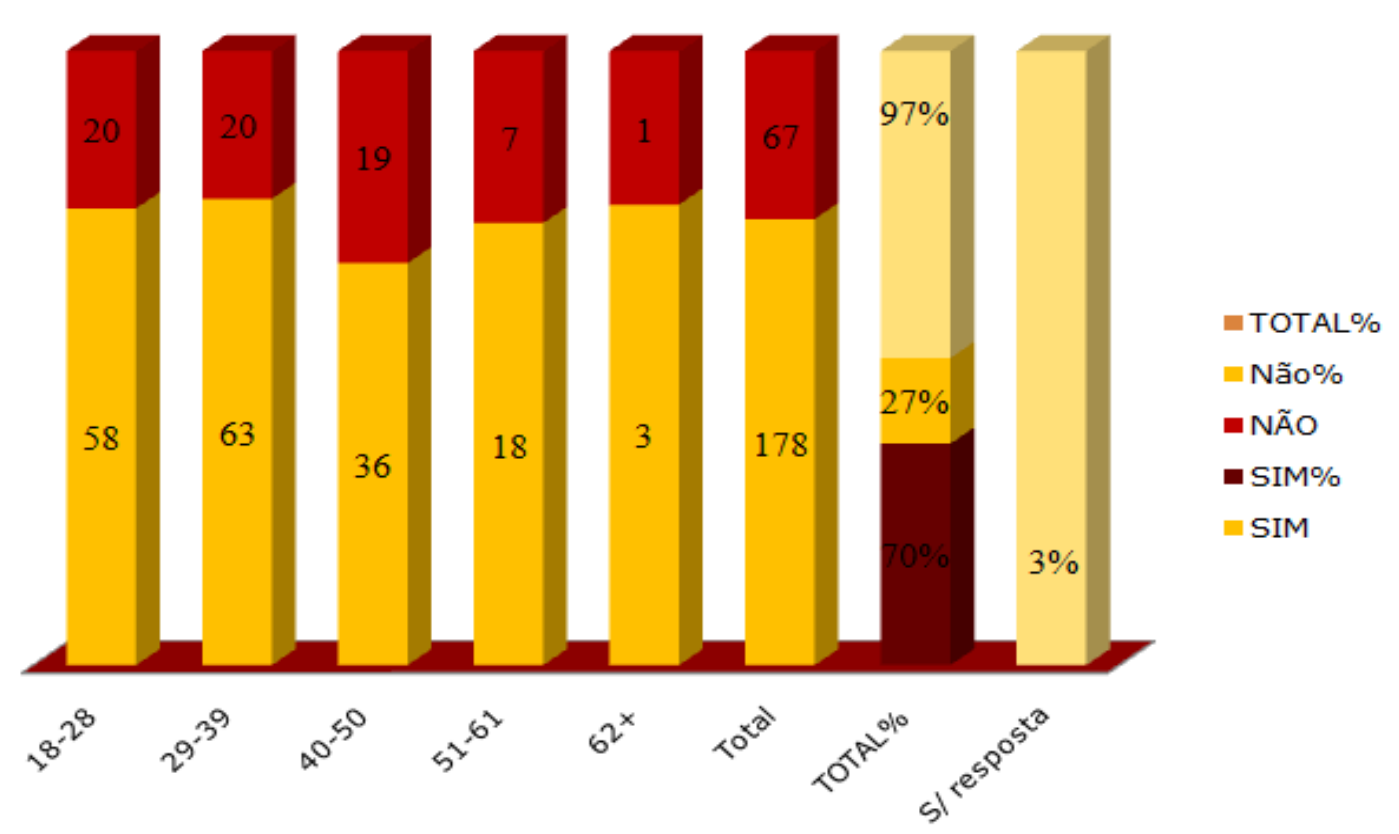


Sabe-se que neste setor as inovações são constantes, tanto em cosméticos, quanto em aparelhos com tecnologia de ponta. Para se informar a respeito, entre as quatro opções apresentadas, internet, mídia impressa, workshops e boca a boca, $77 \%$ das profissionais escolheram os workshops como segunda opção; depois, veio a internet e, por último, a mídia impressa.

O diferencial neste ramo de ocupação está no embasamento técnico e científico, na experiência, na qualidade do atendimento e na atualização profissional que o próprio mercado exige por ser tão competitivo. Cientes disso, as esteticistas participam de cursos de atualização e, em sua maioria, trimestralmente. Como a área está em constante evolução, questionadas sobre um lançamento com um ativo da moda e a fidelidade a ele, apenas $1 \%$ não escolhe um produto da "moda" para trabalhar.

O termo "moda" remete a um período de tempo, a uma fase e, no caso de uso de cosméticos, o ativo da moda pode representar uma tendência, uma característica de um protocolo de tratamento ou até algo que vai além do esperado. A aceitação de um produto com um ativo da "moda" também faz com que as empresas se mantenham atentas sobre a diversificação desse determinado produto e sobre possíveis novas utilizações ou relançamentos.

A mídia nos veículos direcionados à área de estética (revistas impressas e revistas eletrônicas) é fundamental para a aquisição de cosméticos, segundo as profissionais da área. Veja os dados abaixo: 
Tabela 3

Mídia em veículos direcionados é fundamental para a aquisição

\begin{tabular}{ll} 
Idades & Sim \% \\
\hline $18-28$ & $18 \%$ \\
\hline $29-39$ & $22 \%$ \\
\hline $40-50$ & $14 \%$ \\
\hline $51-61$ & $5 \%$ \\
\hline $62+$ & $1 \%$ \\
\hline Total percentual & $60 \%$
\end{tabular}

Gráfico 3

Profissionais que acreditam que a mídia nos veículos direcionados

é fundamental para a aquisição, por idade

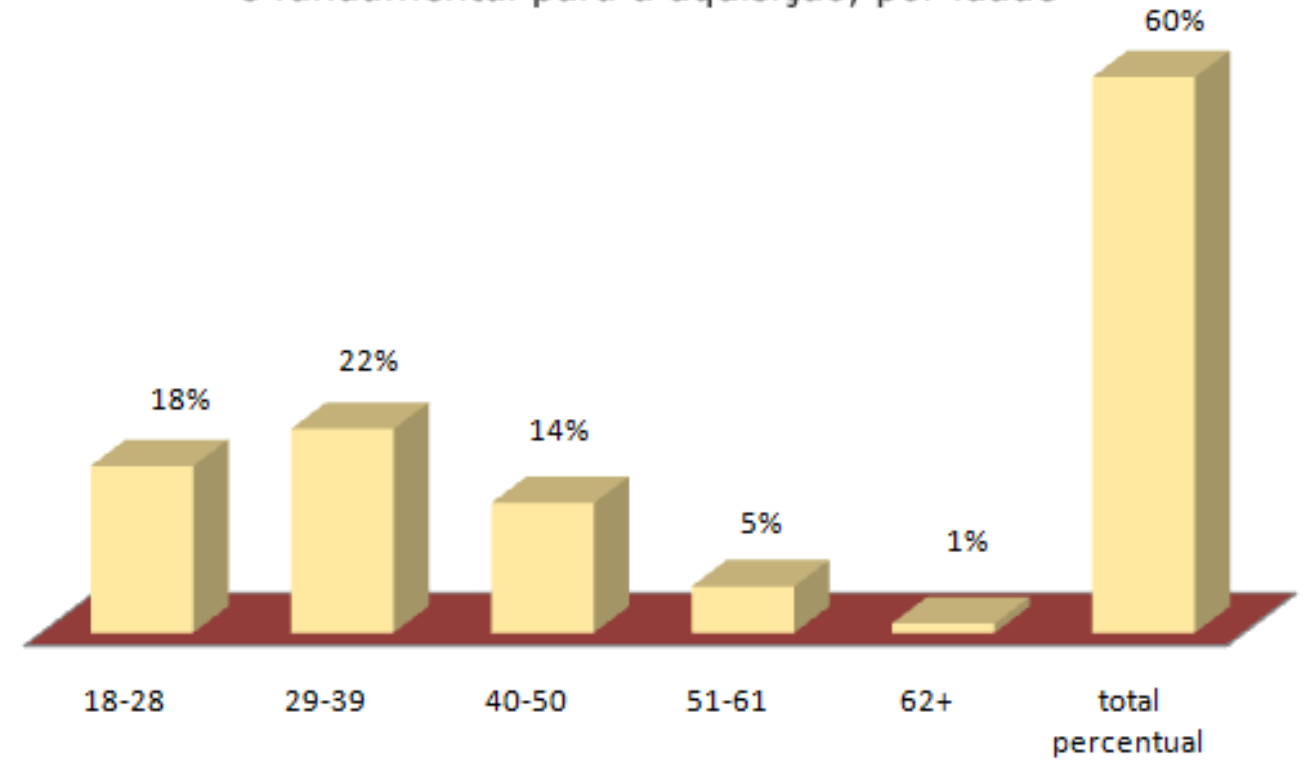


Tabela 4

Mídia nos veículos direcionados é fundamental para a aquisição

\begin{tabular}{ll} 
Idades & Não \% \\
\hline $18-28$ & $11 \%$ \\
\hline $29-39$ & $10 \%$ \\
\hline $40-50$ & $7 \%$ \\
\hline $51-61$ & $4 \%$ \\
\hline Total percentual & $32 \%$
\end{tabular}

\section{Gráfico 4}

Profissionais que NÃO acreditam que a mídia nos veículos direcionados é fundamental para a aquisição, por idade $32 \%$

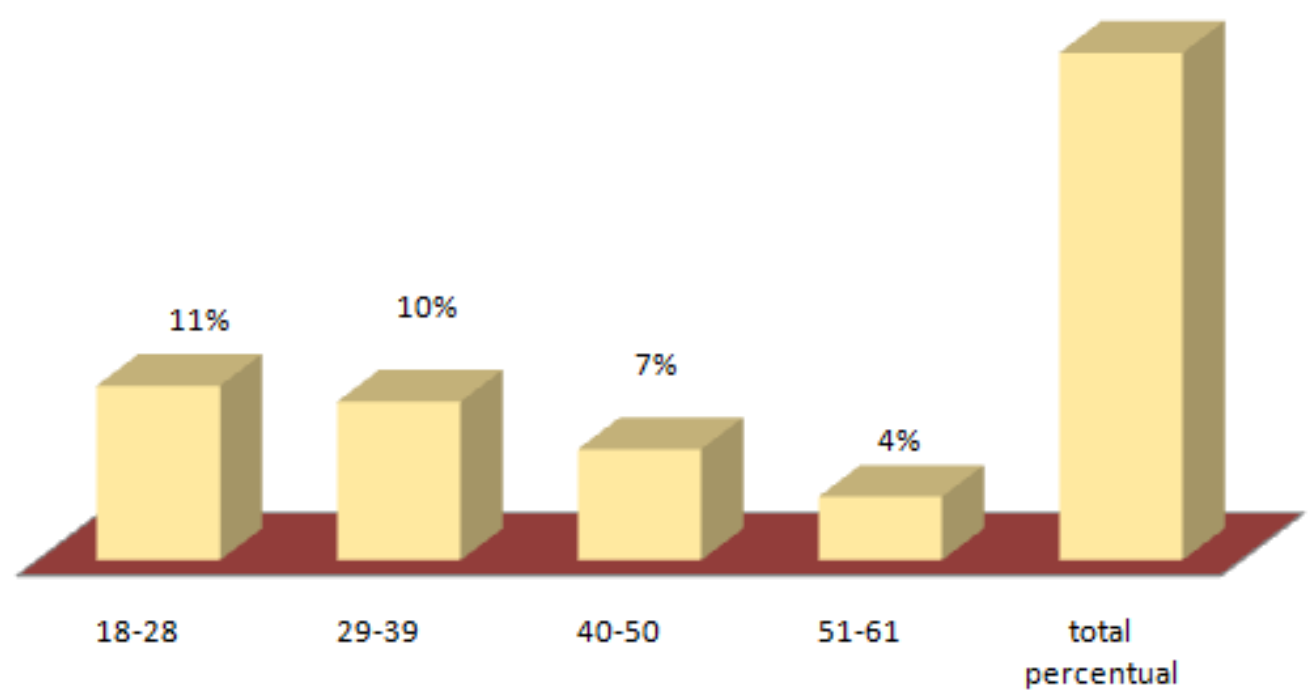

Questionada novamente se a mídia nos veículos impressos é essencial para definir a escolha e a compra de um produto, $64 \%$ responderam que sim. Essas duas questões estão intimamente ligadas à forma de comunicação utilizada para atingir o consumidor, a profissional esteticista. A primeira, 
situando a mídia impressa e eletrônica-internet, e a segunda, apenas a impressa. Uma não desqualifica a outra. A linguagem apresentada em cada veículo e o poder de persuasão contido nas campanhas são fatores que levam a profissional a tomar conhecimento do produto, como consumidora que precisa estar atenta a tudo que diga respeito à execução de seu trabalho, oferecendo mais opções aos clientes.

Mesmo com a constatação de que a mídia é importante fator de decisão para a compra dos cosméticos, as profissionais consideraram as feiras e os eventos e a divulgação dos produtos por outras esteticistas (boca a boca) os itens mais importantes levados em consideração no momento da escolha.

Tabela 5*

Relacione por importância os itens sobre a aquisição*

\begin{tabular}{llllll} 
Itens & 10 & 20 & 30 & 40 & 5 \\
\hline Outras esteticistas & $36 \%$ & $20 \%$ & $13 \%$ & $9 \%$ & $8 \%$ \\
\hline Feiras e eventos & $29 \%$ & $24 \%$ & $21 \%$ & $10 \%$ & $7 \%$ \\
\hline Consultor & $16 \%$ & $17 \%$ & $17 \%$ & $12 \%$ & $11 \%$ \\
\hline Veículos impressos & $12 \%$ & $9 \%$ & $14 \%$ & $19 \%$ & $19 \%$ \\
\hline Internet & $4 \%$ & $16 \%$ & $12 \%$ & $21 \%$ & $24 \%$ \\
\hline S/ respostas & $3 \%$ & $14 \%$ & $23 \%$ & $29 \%$ & $31 \%$
\end{tabular}

*Contagem geral com as 250 esteticistas 


\section{Gráfico 5*}

\section{Relacione por importância os itens sobre aquisição de cosméticos}

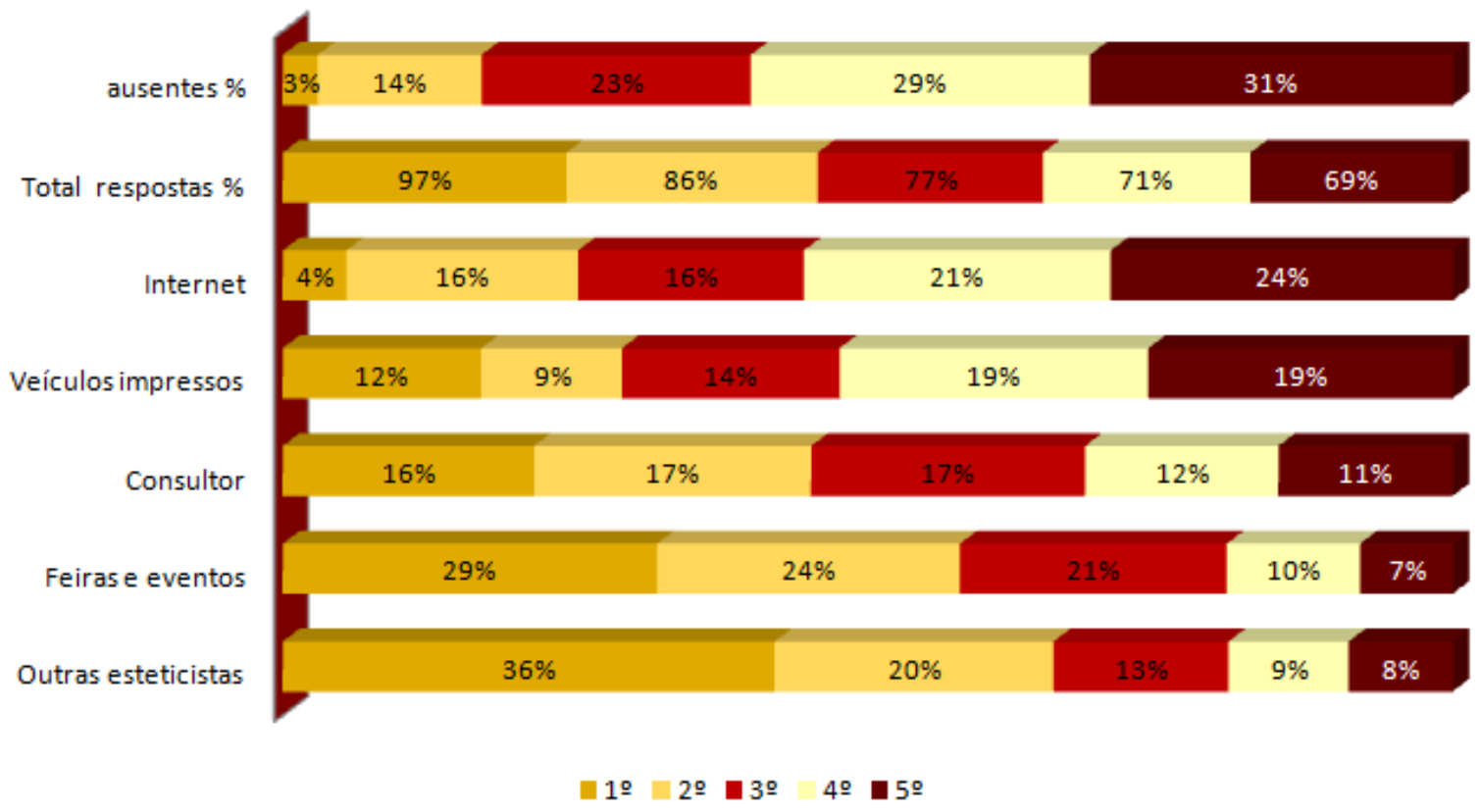

*Por ordem de importância, para a aquisição de produtos cosméticos, ficaram relacionados: em 10 lugar, a opinião de outras esteticistas; em 20 lugar, feiras eventos; em 30, lugar consultor; em 40 lugar, veículos impressos e, em 50 lugar, internet.

\section{Conclusão}

Independentemente da faixa etária e de pequenas variações, não significativas estatisticamente, sobre a utilização maior ou menor da internet e a sua influência, nota-se que, no caso específico das esteticistas, as informações transmitidas de profissional para profissional ou em workshops, feiras e eventos ainda têm maior peso nas decisões das esteticistas.

Todas são unânimes em salientar a importância da mídia em suas escolhas, mas ela não influencia, de forma direta, os julgamentos da categoria no que se refere à aquisição de seus produtos profissionais. É possível arriscarse em sugerir que elas são consumidoras em outras áreas e, por isso, sabem da 
importância da mídia. Mas a fórmula que é utilizada quando são consumidoras finais não se aplica ao tipo de publicidade voltada a elas como esteticistas, já que necessitam de informações técnicas em veículos especializados.

Há uma lacuna nesse processo que talvez mereça a atenção dos profissionais de marketing e propaganda, no sentido de descobrir que outra motivação pode fazer que a publicidade, em veículos impressos direcionados para a área e na internet, torne-se mais atrativa e eficaz para essa classe. Possivelmente, a entrada no mercado editorial de publicações com rigor científico seja uma resposta. 


\section{Referências}

BRUGNAGO, G.; VIEIRA, R. F. A influência do belo no consumo de cosméticos. Trabalho de Conclusão de Curso. Universidade do Vale do Itajaí: Balneário Camboriú, 2007.

CANÇADO, P. "O Brasil porta a porta". In: Isto É Dinheiro, São Paulo, n. 305, 2 julho 2003. Disponível em: <http://www.istoédinheiro.com.br/edicoes/274>. Acesso em: 11 mar. 2001.

ESTATÍSTICAS, DADOS E PROJEÇÕES ATUAIS SOBRE A INTERNET NO BRASIL. Disponível em: <http://www.tobeguarany.com/internet_no_brasil.php>. Acesso: em 16 mar. 2010.

FEBRAPE. "Ofício 009/2005". Disponível em: <http://www.belezain.com.br/estetica/ cartafebrape.asp>. Acesso em: 11 mar. 2010.

GALINDO, D. Comunicação Interativ@. São Paulo, Futura, 2002.

HOJE É DIA DO ESTETICISTA. Ministério do Trabalho e Emprego. Disponível em: <http:// portal.mte.gov.br/imprensa/hoje-e-dia-do-esteticista.htm>. Acesso em: 9 mar. 2010.

JORGE, M. A. M. A comunicação nos anúncios de estética: uma abordagem ética. 22 jan. 2009. Disponível em: <http://www.webartigos.com>. Acesso: 17 mar. 2010.

QUEIROZ, J. P. de; PEREIRA, J. de A.; HUERTAS, M. K. Z. "Propaganda na internet: uma análise de conteúdo das estratégias e estruturas de execução de mensagens no Brasil". In: $32^{\circ}$ Encontro da Anpad - Associação Nacional de Pesquisa em Administração, 2008, Rio de Janeiro - RJ. Anais... Disponível em: <http://www.cesnor.ufsm.br>. Acesso em: 17 mar. 2010.

RIBEIRO, M. P. Gramática aplicada da língua portuguesa. Rio de Janeiro: Metáfora, 2005.

SEBRAE-SC. Inovação, o marketing boca a boca. 16 jul. 2004. Disponível em: <http:// www.sebrae-sc.com.br>. Acesso em: 17 mar. 2010.

SHIMP, T. A. Propaganda e Promoção: Aspectos complementares da comunicação integrada de marketing. Porto Alegre: Bookman, 2002.

UNIVERSIDADE DE WARTHON. O que é o "Marketing boca a boca" afinal de contas? 
Disponível em: <http://www.wharton.universia.net/>. Acesso: em 15 mar. 2011.

\section{Páginas na internet}

Abihpec - Associação Brasileira da Indústria de Produtos de Higiene Pessoal, Perfumaria e Cosmética: http://www.abihpec.org.br/. Acesso em: 15 mar. 2010.

Avon Cosméticos: http://avoncompany.com. Acesso em: 16 mar. 2010.

IBGE - Instituto Brasileiro de Geografia e Estatística: http://www.ibge.gov.br/home/. Acesso em: 10 fev. 2010.

Instituto Euromonitor: http://www.euromonitor.com. Acesso em: 16 mar. 2010

MEC - Ministério da Educação e Cultura: http://emec.mec.gov.br. Acesso em: 4 mar. 2010.

Natura Cosméticos: http://natura.infoinvest.com.br. Acesso em: 16 mar. 2010.

Senac - Serviço Nacional de Aprendizagem Comercial: http://www.senac.br. Acesso em: 22 fev. 2010. 
1 Coordenadora e orientadora do curso de pós-graduação em estética da UGF (Universidade Gama Filho). É doutora em reabilitação pela Unifesp (Universidade Federal de São Paulo), mestre em educação e interdisciplinaridade, especialista em educação e ciências morfológicas, esteticista e biomédica. É presidente do Sindicato Laboral das Esteticistas do Estado de São Paulo.

2 Formada em comunicação social pela FIAM (Faculdades Integradas Alcântara Machado- grupo FMU), com bacharelado em jornalismo. Atuou por mais de 10 anos na profissão e, atualmente, é pós-graduanda em estética pela Universidade Gama Filho.

3 Fonte: Suely Melnick, empresária proprietária da Nova Imagem Cosméticos e diretora administrativa da Escola Técnica Estética Integral Nova Imagem.

4 Fonte: Silvestre Mendonça de Resende, diretor institucional da Valmari Cosméticos

5 Fonte: Paula Ricupero, do departamento de Marketing da Vitardem Hipoalergênicos

6 Fonte: Graziella Marques Billá, do departamento de Comunicação da Buona Vita Cosméticos

7 Fonte: Nádia Santana, assessoria de imprensa da Vitaderm 